\title{
Are the Immunocompetence and the Presence of Metazoan Parasites in Cyprinid Fish Affected by Reproductive Efforts of Cyprinid Fish?
}

\author{
Karolína Rohlenová and Andrea Šimková \\ Department of Botany and Zoology, Faculty of Science, Masaryk University, Kotlářská 2, 61137 Brno, Czech Republic
}

Correspondence should be addressed to Andrea Šimková, simkova@sci.muni.cz

Received 31 July 2009; Accepted 23 October 2009

Academic Editor: Jorge Morales-Montor

Copyright ( $\odot 2010$ K. Rohlenová and A. Šimková. This is an open access article distributed under the Creative Commons Attribution License, which permits unrestricted use, distribution, and reproduction in any medium, provided the original work is properly cited.

\begin{abstract}
Each organism has the limited resources of energy that is distributed among important life traits. A trade-off between immune response and other physiological demands of organism especially costly reproduction is expected. Leuciscus cephalus, the cyprinid fish, was investigated during three periods varying in reproductive investment, that is, before-breeding, breeding, and afterbreeding periods. We tested whether a potentially limited investment in immunity during the breeding is associated with higher susceptibility to the metazoan parasites. Following the immunocompetence handicap and sperm protection hypotheses, males expressing more elaborated sexual ornamentation should produce better quality sperm and be more parasitized. We found that reproductive investments in fish play an important role for energy allocation into somatic condition, immunity, and reproduction. The immune parameters including respiratory burst and leukocyte count were higher in breeding; however, parasite species richness and abundance appeared low. Males investing more in spawning tubercles reached high spermatocrite and were more parasitized by digeneans.
\end{abstract}

\section{Introduction}

Life-history theory predicts that each organism has a limited amount of energy, which is allocated among the traits connected with maintenance, reproduction, and growth [1, $2]$. One of the most important life traits involving the potential life trade-offs is the ability of immune system to defend hosts against parasites. Thus recently, the investment in immune defence is a matter of great concern in the immunoecological or evolutionary immunology studies [3].

There are several studies investigating the importance of immunological competence as a potential determinant of reproductive success and fitness predominantly using birds as a model (e.g., [4-7]). The main presumption of those studies is that the host immune system is exposed to the variety of parasite species; therefore, hosts have to develop adequately strong immune response to reduce the fitness cost due to parasitism.
Immune system of each organism could be a subject of rapid temporal changes due to limited resources of energy, especially in reproductive period, such as breeding in fish. The changes should be achieved either by trade-off between immunity and reproduction or by adaptive or nonadaptive immunomodulative action of sex hormones [8]. The costs paid for reproduction due to immunosuppression by steroid hormones were suggested for salmonid Artic charr (Salvelinus alpinus), following the observation that spawning males were more susceptible to parasite infection and had smaller spleen size in comparison with the resting males [9]. A tradeoff in energy allocation could also explain a negative relationship between immunocompetence (measured by spleen size) and condition factor (measurement of fish vigour and health) found in fish males, previously observed in common bream (Abramis brama) during breeding period [10]. The sexual ornamentation in fish males during spawning seems to reflect the potential costs of reproduction caused by 
higher parasite infection although there was no effect on immunocompetence measured by spleen size.

Following the hypotheses of evolution of sexual selection, the expressed sexual traits like sexual ornamentation could be considered as a male handicap playing a key role in mate choice. The more intensive expression of sexual trait indicates the presence and effectiveness of genes for resistance (so-called "good genes") against pathogens and parasites [11]. Many studies using different models have been conducted to investigate the associations between parasite loads and intensity of sexual ornamentation but their results are various (see [12-14]). Studies based on measurements of immune function provided stronger evidence for the Hamilton and Zuk hypothesis than those based on measures of parasite load [13]. Immunocompetence handicap hypothesis introduced by Folstad and Karter [15] is based on presumption of dualistic role of steroid hormones. On the one hand, those hormones stimulate the increase in the expression of sexual ornamentation, but on the other hand, they decrease the resistance and immune defence of individuals by immunosupression. The role of steroid hormones, mainly in testosterone-mediated immunosuppression, was also highlighted by sperm protection hypothesis $[16,17]$. Males able to tolerate the negative effect of testosterone produce more developed sexual traits and also the sperm of better quality. Therefore, they are supposed to be more susceptible to parasites because their immune response is suppressed by testosterone. This hypothesis was partially supported in roach (Rutilus rutilus), a freshwater cyprinid fish [18].

Leuciscus cephalus is the cyprinid fish spawning usually to sand or gravel bottom from May to June [19]. The spawning period is determined by water temperature. During the spawning period, males produce keratin-based epidermal nodules-breeding tubercles - which are invoked by several pituitary and sex hormones [20]. The breeding tubercles may have a role as a status badge or as a sign of quality [21], or they are important in mate choice indicating male's parasite load to females [22] and resistance to parasites or pathogens [23]. Taskinen and Kortet [23] found a positive relationship between proportions of dead Rhipidocotyle campanula (Digenea) and sexual ornamentation in three populations of roach in accordance with HamiltonZuk hypothesis. Skarstein and Folstad [24] documented a negative association between lymphocyte density and sexual ornamentation (red spawning coloration) in Artic charr which may indicate the increased investment in sexual ornamentation at the costs of immunity.

The aim of the present study was to investigate the changes in immune defence, condition status, reproduction parameters, and parasitism in selected cyprinid fish species in the periods of different reproductive investment, following the hypothesis of potential trade-offs in energy allocation. We supposed and tested whether a potentially limited investment in immunity is associated with higher susceptibility to the metazoan parasites (including especially helminths) during the period of high reproductive investment (i.e., spawning period). Finally, following the predictions of immunocompetence handicap and sperm protection hypotheses, we tested whether males expressing more elaborated sexual ornamentation produce better quality sperm (measured by sperm density) and are parasitized by high parasite species richness due to potential immunosuppresion by steroid hormones.

\section{Materials and Methods}

2.1. Fish Sampling. A total of 90 males of chub (Leuciscus cephalus, Cyprinidae) were collected in 2005 during three different periods in relation to reproduction investment. Those periods included before breeding in early May, breeding in late May, and after breeding in late June. The fish was collected from the same locality situated on the confluence of the Svitava and Svratka rivers, belonging to the Morava river basin on the periphery of Brno (Czech Republic). The fish individuals were captured using electrofishing and immediately a blood sample $(340 \mu \mathrm{L})$ was taken from individually electronarcotized fish. Cardiac puncture using heparinized syringes was used as an optimal sampling method in electronarcosis to collect fish blood [25]. Blood samples were collected in heparinized microtubes and mixed with heparin diluted $10 \mathrm{x}$ with $0.7 \% \mathrm{NaCl}$ to retain the number of heparin units in the measured blood according to the methodology written by Kubala et al. [26]. After blood sampling, the fish were placed in a tank containing water collected from the same location and then transported to the laboratory. During the storage in the laboratory tanks, the original water temperature was maintained and a standard aquarium filter was used for water filtration. All fish individuals were killed within 24 hours. Each individual was measured (total and standard lengths in $\mathrm{mm}$ ) and weighed (in g), and a complete parasitological dissection of the fish according to Ergens and Lom [27] was performed.

The physiological parameters, including gonad weight and spermatocrit, hematocrit, and erythrocyte counts, and the selected immune parameters, including spleen weight, leukocrit and leukocyte counts, differential leukocyte cell counts, phagocyte count, and respiratory burst activity, were measured. We calculated relative body weight (condition factor, $K$ ) using the equation: $K=$ constant $\times$ somatic weight $(\mathrm{g}) /(\text { standard length }(\mathrm{cm}))^{3}$. According to Bolger and Connolly [28], the assumption of the condition factor is that the heavier the fish is in relation to its length. Therefore, it is better to use the general condition rather than the weight and length particularly. The relative size of gonads, that is, gonado-somatic index, GSI, was calculated as follows: GSI = gonad weight $(\mathrm{g}) /$ body weight $(\mathrm{g}) \times 100$. Spleen-somatic index, SSI, was calculated as spleen weight $(\mathrm{g}) /$ body weight (g) $\times 100$.

2.2. Parasite Collection and Determination. The complete dissection of fish was performed using the method of Ergens and Lom [27]. Fish individuals were investigated for all metazoan parasites. Ectoparasites (Monogenea, Hirudinea, and Mollusca) and endoparasite helminths (Digenea, Cestoda, Acanthocephala, and Nematoda) were determined using recent keys and methodology [27, 29-32]. All recorded 
specimens of metazoan parasites, that is, Monogenea in glycerin-amonium picrate, Nematoda in glycerin-ethanol and other metazoan parasites (Digenea, Cestoda, Acanthocephala, and Mollusca) in 4\% formalin were fixed. Digenea and Cestoda were subsequently stained using IAC carmine [33]. A light microscope (Olympus BX 50) with phasecontrast, differential interference contrast (DIC according to Nomarski), and Digital Image Analysis (Micro Image 4.0 for Windows) was used for parasite determination and measurements.

2.3. Blood Analyses. Differential cell counts were estimated in whole blood smears stained panoptically by the Pappenheim technique (May-Grünwald and Giemsa-Romanovsky) [34]. We considered 200 leukocytes and classified them using morphology into following categories: lymphocytes, monocytes, blasts, and neutrophiles (including the different neutrophiles stages, i.e., myelocytes, metamyelocytes, bands and segments) according to Svobodová et al. [34]. Erythrocyte (in T. $\mathrm{l}^{-1}$ ) and leukocyte (in G. $\mathrm{l}^{-1}$ ) counts were executed in Bürker's hemocytometer. Heparinized blood was diluted with Natt-Herick solution at 1:200 ratio in special $25 \mathrm{~mL}$ flask [35, 36]. Hematocrit and leukocrit (in $1.1^{-1}$ ) were measured using heparinized microcapillaries $75 \mathrm{~mm}$ long and $60 \mu \mathrm{m}$ in inner volume. Centrifugation was carried out with a hematocrit centrifuge at $12000 \mathrm{~g}$ for 3 minutes [35]. Differential leukocyte count and total count of leukocytes were used to calculate the relative count of phagocytes $\left(G .1^{-1}\right)$. According to Šterzl [37] concerning neutrophiles, only metamyelocytes or older stages than metamyelocytes are considered to have phagocytic ability. Therefore, the relative count of phagocytes in our study included monocytes, neutrophilic metamyelocytes, bands, and segments.

\subsection{Respiratory Burst Activity. Chemiluminescence (CL)} activated with opsonised zymosan was measured in each fish sample. The chemiluminescence emission (in relative light units, RLU) was measured in five-minute intervals during 100 minutes (i.e., a total of 20 measurements were taken) to obtain the kinetic curves for each sample. The peak of the CL signal, that is, the maximal value of a respiratory burst (RB), was used for each individual. CL measurements were carried out with a Luminometer Junior (Checklight; 380-630 nm) according to methodology of Kubala et al. [26].

2.5. Sperm Quality and Sexual Ornamentation. The selected parameters potentially reflecting the quality of male individuals were measured only during the spawning period. Spermatocrit (in $1.1^{-1}$ ), a measurement of sperm concentration expressing the percentage of a given volume of milt occupied by sperm cells was analyzed according to Kortet et al. [18]. The microcapillaries with milt samples were centrifuged for 5 minutes at $12000 \mathrm{~g}$. We calculated all breeding tubercles, as secondary sexual ornaments in fish, on the head and operculum of each individual.

2.6. Data Analysis. Each parasite group was characterized by the following epidemiological parameters: prevalence (percentage of infected host individuals in each period) and intensity of infection (number of parasites per an infected host) according to Bush et al. [38]. Moreover, abundance as a number of parasites in all investigated hosts in each period was calculated. Only parasite groups with high epidemiological values, including Monogenea, Digenea, Cestoda, and Acanthocephala, were used for statistical analyses. The differences in physiological, immune parameters, and parasitism among 3 investigated periods were tested using ANOVA. Tukey HSD post hoc test was applied for multiple pairwise comparisons. The potential relationships among the studied variables were analyzed using a Principal Component Analysis (PCA) and Pearson's correlation coefficient. Bonferroni correction for multiple tests was applied. Most of variables analyzed did not fit a normal distribution, and therefore, they required a transformation using logarithm (for GSI, SSI, respiratory burst, count of erythrocytes, and number of head tubercles), arcsine square root (for spermatocrit), and square root (for parasite abundance and total parasite species richness). No transformation was necessary for condition factor and count of phagocytes. GSI and SSI instead of gonad or spleen weights were used in PCA to eliminate the effect of body weight on gonad or spleen weights. All statistical analyses were executed using Statistica 8.0.

\section{Results}

3.1. Physiological and Immunological Parameters. As can be concluded from the results, the significant differences were found in the measured physiological and immune parameters when comparing the three periods which varied in the investment in reproductive activity (i.e., beforebreeding, breeding, and after-breeding). The mean and standard deviations $( \pm \mathrm{SD})$ of total body length, body weight, gonad weight, spleen weight, and condition factor of fish within each period investigated are shown in Table 1.

We tested the differences in physiological and immune parameters among 3 investigated periods using ANOVA. The statistically significant differences were found for GSI $\left(\mathrm{F}_{2,82}=106.250, P<.0001\right)$, condition factor $\left(\mathrm{F}_{2,87}=7.150\right.$, $P=.0013)$, respiratory burst $\left(\mathrm{F}_{2,84}=7.113, P=.0014\right)$, erythrocyte $\left(\mathrm{F}_{2,87}=3.704, P=.0286\right)$ and leukocyte $\left(\mathrm{F}_{2,87}\right.$ $=6.151, P=.0032)$ counts, hematocrit $\left(\mathrm{F}_{2,85}=3.491, P\right.$ $=.0349)$, and leukocrit $\left(\mathrm{F}_{2,85}=3.331, P=.0405\right)$. The highest values of GSI, condition factor, and hematocrit were recorded in before-breeding period while erythrocyte count revealed the highest values in after-breeding period. The maximal values of immune parameters, including respiratory burst, leukocyte count, and leukocrit, were found in breeding period. However, no significant difference was shown for SSI and phagocyte count among three periods of different reproductive investments (ANOVA, $P>.05$ ). Using Tukey HSD post hoc test we compared differences between all pairs of periods. First, we detected significant differences between all periods for GSI $(P<.05)$. Consequently, we found the significant differences of before-breeding period in comparison with both breeding and after-breeding periods 
TABLE 1: Data on the fish investigated: $n$ presents the number of males collected, total body length, body weight, gonad weight, spleen weight, and condition factor $(K)$ : means \pm SD are shown.

\begin{tabular}{lccccccccrrr}
\hline \multirow{2}{*}{ Sampling period } & \multirow{4}{*}{$n$} & \multicolumn{2}{c}{ Total length $(\mathrm{mm})$} & \multicolumn{2}{c}{ Body weight $(\mathrm{g})$} & \multicolumn{2}{c}{ Gonad weight $(\mathrm{g})$} & \multicolumn{3}{c}{ Spleen weight $(\mathrm{g})$} & \multicolumn{2}{c}{$K$} \\
& & Mean & \pm SD & Mean & \pm SD & Mean & \pm SD & Mean & \pm SD & Mean & \pm SD \\
\hline Before-breeding & 29 & 271.59 & \pm 3.25 & 245.37 & \pm 106.88 & 21.88 & \pm 10.98 & 0.27 & \pm 0.13 & 1.92 & \pm 0.22 \\
Breeding & 31 & 270.39 & \pm 26.93 & 215.97 & \pm 61.39 & 10.30 & \pm 3.57 & 0.25 & \pm 0.09 & 1.76 & \pm 0.17 \\
After-breeding & 30 & 260.52 & \pm 71.48 & 215.49 & \pm 63.92 & 10.51 & \pm 3.79 & 0.25 & \pm 0.08 & 1.60 & \pm 0.43 \\
\hline
\end{tabular}

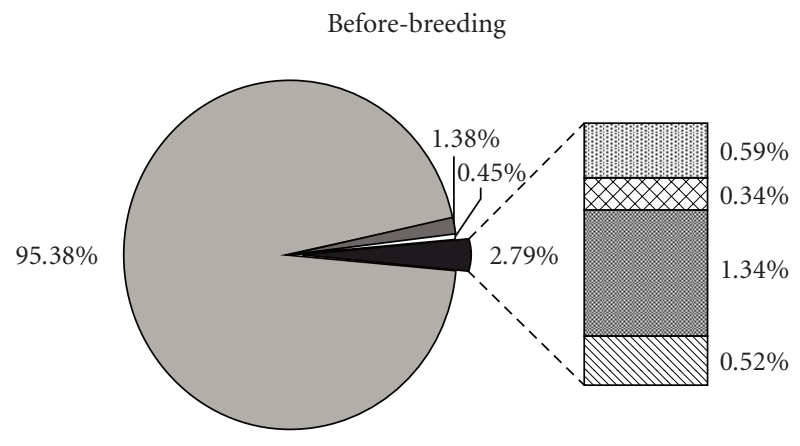

(a)

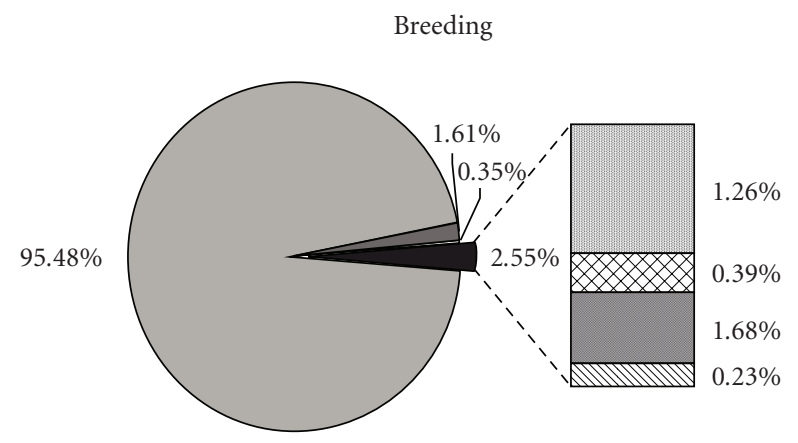

(b)

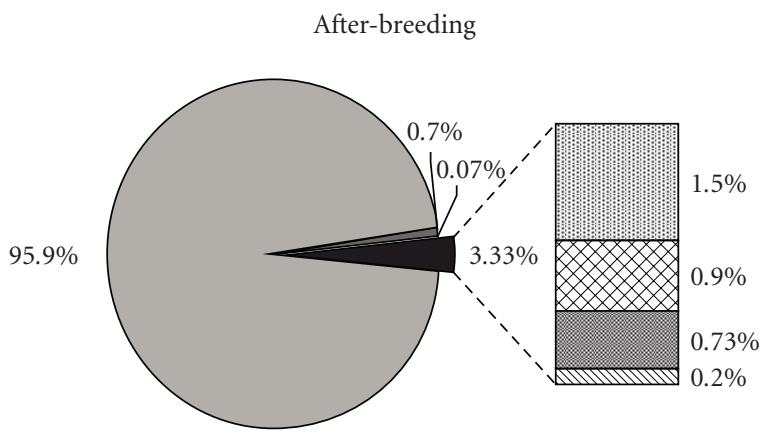

\begin{tabular}{|c|c|}
\hline$\square$ Lymphocytes & N. myelocytes \\
\hline Monoctyes & $\otimes$ N. metamyelocytes \\
\hline Blasts & N. bands \\
\hline Neutrophilic granulocytes & $\mathbb{N}$ N. segments \\
\hline
\end{tabular}

(c)

Figure 1: Changes in leukocyte differential count in three periods investigated. for condition factor and leukocyte count. Further, the significant differences $(P<.05)$ were also found between before-breeding and breeding periods for respiratory burst and hematocrit and between before breeding and afterbreeding for erythrocyte count and leukocrit.

As revealed by comparison of differential leukocyte count among the three periods studied, only small variability in the composition of white blood cell components was found. Blood of chub showed lymphocytic character, that is, lymphocytes prevailed in the white blood cell. The proportion of lymphocytes reached the similar values in all three periods. Only a small difference was found in the proportions of monocytes, total neutrophilic granulocytes, and blasts in relation to three periods investigated (Figure 1). Nevertheless, the variations were found in proportions of the developmental stages of neutrophilic granulocytes including early ontogenetic stages, that is, myelocytes and metamyelocytes as well as late ontogenetic stages, that is, bands and segments. We recorded the low proportion of neutrophilic myelocytes and metamyelocytes and the high proportion of bands and segments in before-breeding period. On the other hand, in breeding and after-breeding periods, we found higher proportions of early ontogenetic stages (myelocytes and metamyelocytes) compared with other development stages of neutrophiles. The percentage distribution of individual types of leukocytes during three periods investigated is shown in Figure 1.

3.2. Parasite Infection. Metazoan parasite species belonging to seven groups including ectoparasitic Monogenea, Hirudinea, Mollusca, and endoparasitic Digenea, Cestoda, Acanthocephala, and Nematoda were found. Monogenea was the species richest group, including eight species. The presence of all parasite species in three periods investigated is shown in Table 2. From a total 22 parasite species, 12 of them occurred in all three periods studied, 7 species were present only in before-breeding and after-breeding periods (i.e., those parasites were absent in breeding period), and 2 parasite species were found solely in breeding period.

When comparing the three periods, we detected a variation in epidemiological characteristics including abundance, intensity of infection, and prevalence. Those characteristics for each parasite group are shown in Table 3. ANOVA test revealed statistically significant differences in abundance among three periods investigated for three parasite groups: Monogenea $\left(\mathrm{F}_{2,87}=10.887, P<.0001\right)$, Digenea $\left(\mathrm{F}_{2,87}=\right.$ $10.257, P=.0001)$, and Cestoda $\left(\mathrm{F}_{2,87}=4.745, P=.0111\right)$. The significant differences for these parasite groups were 
TABLE 2: Presence (+) and absence (-) of parasite species in each sampling period. Hatching areas indicate the presence of a given species in all three periods investigated.

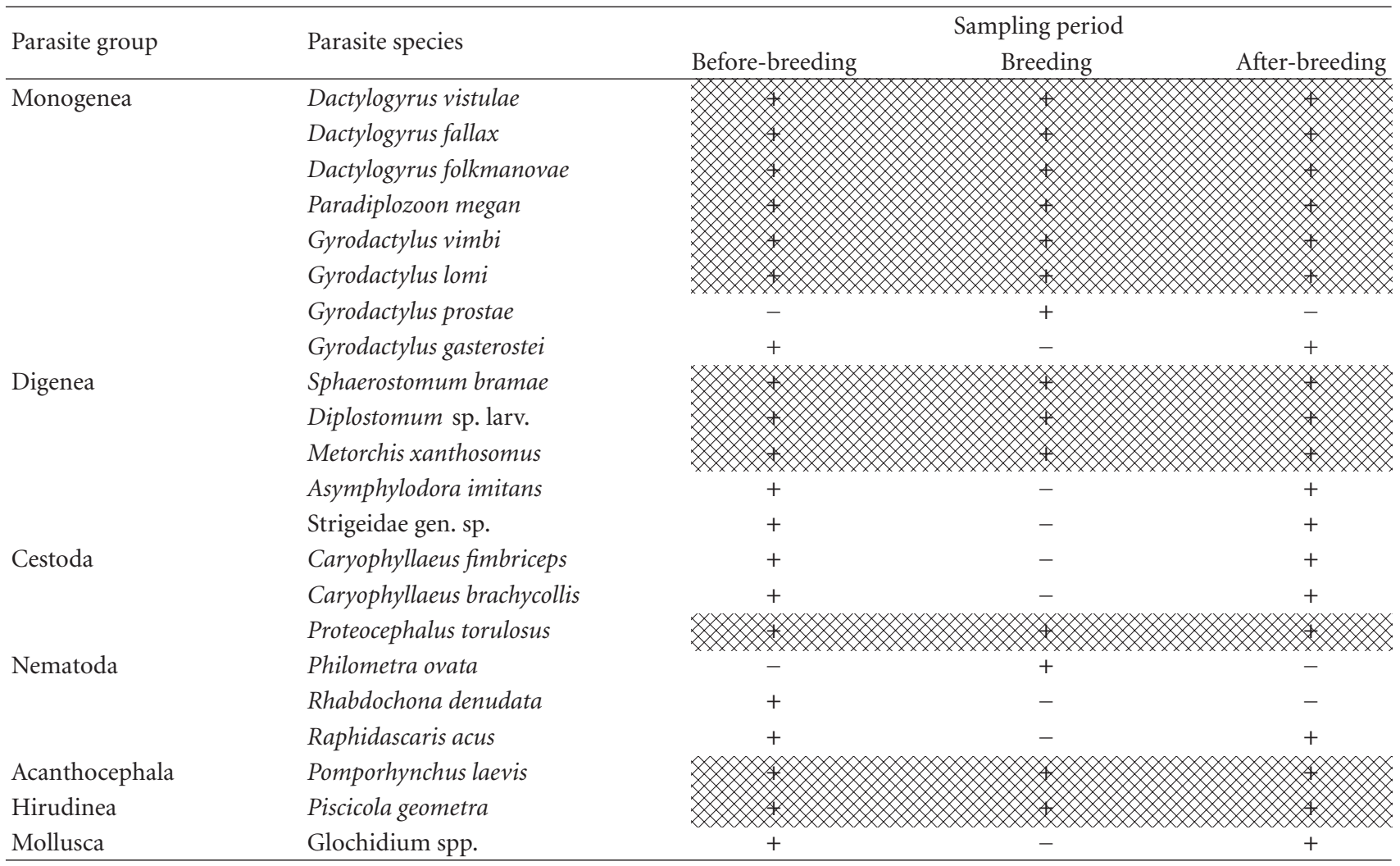

also found after using Bonferonni correction $(P<.05)$. The highest abundance of Monogenea was recorded in afterbreeding period. Digenea and Cestoda reached the maximal values of abundance in before-breeding period. Using post hoc test for pairwise comparison, we found statistically significant differences between before-breeding and afterbreeding as well as breeding and after-breeding periods for abundance of Monogenea and Digenea (both $P<.05$ ). Further, the significant differences for Cestoda were seen between before- and breeding periods $(P<.05)$.

3.3. Associations between Immunity, Physiological Parameters, and Parasite Infection. The potential correlations between immunocompetence, physiological parameters and parasitism were investigated in three periods varying in the reproduction investment. After transforming data to achieve the normal distribution, the following parameters were used for the analyses: (1) immunological data (SSI, respiratory burst, and count of phagocytes), (2) physiological data (GSI, condition factor, count of erythrocytes, spermatocrit, and number of head tubercles), and (3) parasitism. For each period two measurements of parasitism were applied, that is, total parasite species richness and parasite abundance. The second one includes abundances of the most numerous parasite groups, that is, Monogenea (all of them gill and skin parasites), Pomporhynchus laevis (Acanthocephala), and Cestoda (including three intestinal parasite species) and two numerous parasite species of Digenea, that is, Sphaerostomum bramae and Metorchis xanthosomus, were treated separately because of different location (intestine or skin) and strategy (adult or larvae stages) in hosts. The graphic outputs of PCA analyses using parasite abundance as a measurement of parasite load in Figures 2-4(a), (b) and total parasite species richness in Figures 2-4(c), (d) are shown. The first three axes explain the highest proportion of total variability and therefore they are retained for graphic interpretation (see Table 4 for the variability explained by the first three axes).

In before-breeding period, the analyses showed that fish condition in before-breeding period was positively correlated to abundance of Metorchis xanthosomus $(R=0.4129$, $P<.0001)$ and negatively to Sphaerostomum bramae $(R=$ $-0.6582, P=.040$ ) (see Figures $2(\mathrm{a})$ and 2(b)). Following PCA results, GSI is negatively associated to Monogenea abundance (Figure 2(b)). Moreover, GSI is associated to SSI in before-breeding period (Figures 2(c) and 2(d)). The total parasite species richness increased with higher SSI and lower GSI (Figure 2(c)). Nevertheless, the correlations between those variables were not significant $(P>.05)$.

In breeding period, we found a positive correlation between the number of head tubercles and spermatocrit $(R=$ $0.4009, P=.038$ ) (see Figures 3(a), 3(b), and 3(c)). Following PCA results, GSI tends to be positively associated with both spermatocrit and number of head tubercles (Figures 3(a) and $3(\mathrm{c}))$. However, the correlations were not significant 
TABLE 3: Basic epidemiological characteristics: abundance (mean \pm SD), intensity of infection ( $\min -\max )$, and prevalence (percentage of infected hosts) of all metazoan parasite groups.

\begin{tabular}{|c|c|c|c|c|}
\hline Parasite group & Abundance & $\pm \mathrm{SD}$ & Intensity of infection & Prevalence (in \%) \\
\hline \multicolumn{5}{|c|}{ Before-breeding } \\
\hline Monogenea & 49.76 & \pm 27.97 & $8-116$ & 100.00 \\
\hline Hirudinea & 0.10 & \pm 0.41 & $0-2$ & 6.90 \\
\hline Mollusca & 0.03 & \pm 0.19 & $0-1$ & 3.45 \\
\hline Acanthocephala & 3.97 & \pm 5.34 & $0-21$ & 75.86 \\
\hline Digenea & 71.83 & \pm 76.79 & $0-378$ & 96.55 \\
\hline Cestoda & 2.03 & \pm 6.74 & $0-36$ & 27.59 \\
\hline Nematoda & 0.10 & \pm 0.31 & $0-1$ & 10.34 \\
\hline \multicolumn{5}{|c|}{ Breeding } \\
\hline Monogenea & 42.61 & \pm 48.46 & $0-186$ & 90.32 \\
\hline Hirudinea & 0.03 & \pm 0.18 & $0-1$ & 3.23 \\
\hline Mollusca & - & - & - & - \\
\hline Acanthocephala & 3.52 & \pm 6.52 & $0-34$ & 67.74 \\
\hline Digenea & 58.13 & \pm 114.3 & $0-474$ & 87.10 \\
\hline Cestoda & 0.03 & \pm 0.18 & $0-1$ & 3.23 \\
\hline Nematoda & 0.10 & \pm 0.3 & $0-1$ & 9.68 \\
\hline \multicolumn{5}{|c|}{ After-breeding } \\
\hline Monogenea & 92.73 & \pm 59.11 & $1-234$ & 100.00 \\
\hline Hirudinea & 0.30 & \pm 0.7 & $0-3$ & 20.00 \\
\hline Mollusca & 0.27 & \pm 1.46 & $0-8$ & 3.33 \\
\hline Acanthocephala & 3.60 & \pm 3.8 & $0-14$ & 76.67 \\
\hline Digenea & 14.17 & \pm 34.04 & $0-180$ & 56.67 \\
\hline Cestoda & 0.20 & \pm 0.55 & $0-2$ & 13.33 \\
\hline Nematoda & 0.03 & \pm 0.18 & $0-1$ & 3.33 \\
\hline
\end{tabular}

$(P>.05)$. Even if there was no correlation between GSI and head tubercles, a positive correlation between gonads and head tubercles was found using gonad weight $(R=$ 0.3943, $P=.042$ ). Moreover, spleen weight was positively correlated to spermatocrit $(R=0.4652, P=.014)$ (not shown in the figure). Further, count of phagocytes was positively correlated to total parasite species richness $(R$ $=0.4958, P=.009$ ) (Figures 3(c) and 3(d)) as well as abundance of Pomporhynchus laevis (Acanthocephala) was positively associated to SSI $(R=0.4434, P=.021)$ (Figure $3(\mathrm{a})$ ) in breeding. Moreover, a positive correlation between abundance of Metorchis xanthosomus and spermatocrite $(R$ $=0.4421, P=.021$ ) (Figures 3(a) and 3(b)) and a negative correlation between total parasite species richness and count of erythrocytes $(R=-0.3822, P=.049)$ (Figures 3(c) and 3(d)) were found.

Using PCA and Pearson's correlation for the data from after-breeding period, abundance of Cestoda was negatively correlated to fish condition $(R=-0.3768, P=.048)$ and phagocyte count $(R=-0.4355, P=.021)$ (Figures $4(\mathrm{a})$ and $4(\mathrm{~b}))$. A negative correlation was also found between phagocyte count and abundance of Sphaerostomum bramae $(R=-0.4268, P=.024)$ (Figures $4(\mathrm{a})$ and $4(\mathrm{~b}))$. Finally, negative correlation between total parasite species richness and both phagocyte count $(R=-0.3871, P=.042)$ and SSI $(R=-0.4059, P=.032)$ were found (see Figures $4(\mathrm{c})$ and $4(\mathrm{~d}))$.

\section{Discussion}

4.1. Differences in Immunity and Physiology. In this study, the differences in fish condition and immunity were hypothesized in relation to reproductive effort of fish. Therefore, we analyzed several immune and physiological parameters of chub, selected cyprinid fish species in three periods which varied in reproductive investment, that is, before-breeding, breeding, and after-breeding periods. The selected immune parameters are widely applied in immunoecological studies of fish. When comparing the immune and physiological variables measurements, we found significant changes in all parameters except relative weight of spleen and phagocyte count. In spite of no significant change in relative phagocyte count, the activity of phagocytes measured by respiratory burst showed significant changes among three periods investigated. The differences in proportion of developmental stages of neutrophiles were also found among the periods of different reproductive investments. It may suggest that the total phagocyte activity is potentially affected by neutrophile profile rather than by total number of phagocytes. Moreover, the individual activity level of neutrophile cells is probably involved in the total signal of respiratory burst. Further, in spite of the fact that the changes in the differential leukocyte count are considered to be one of the most sensitive indicators of acute stress in fish [39], we did not record any noticeable change in percentage of lymphocytes and total 


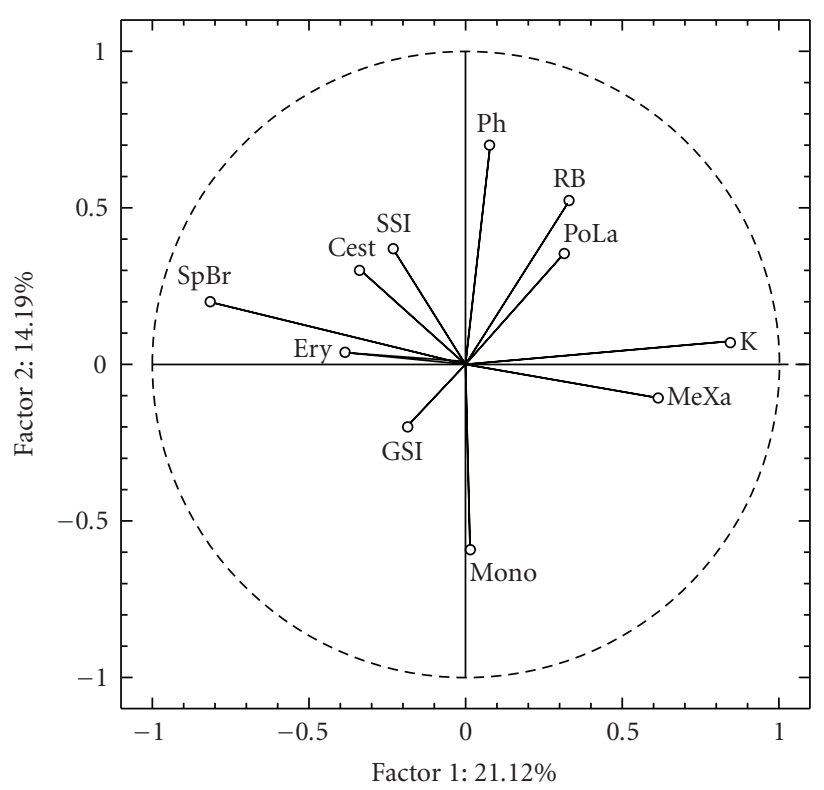

(a)

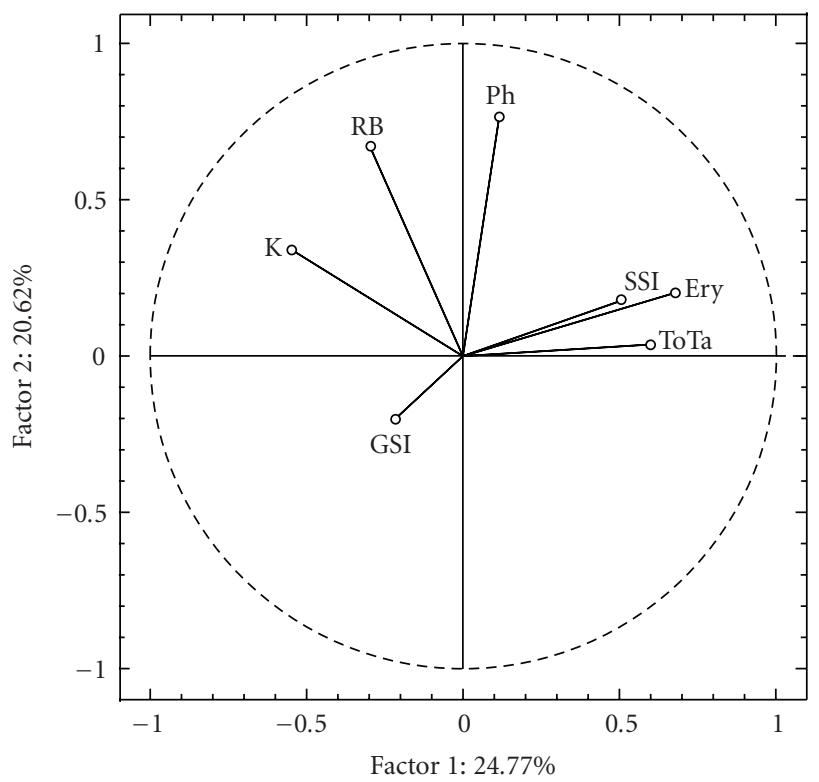

(c)

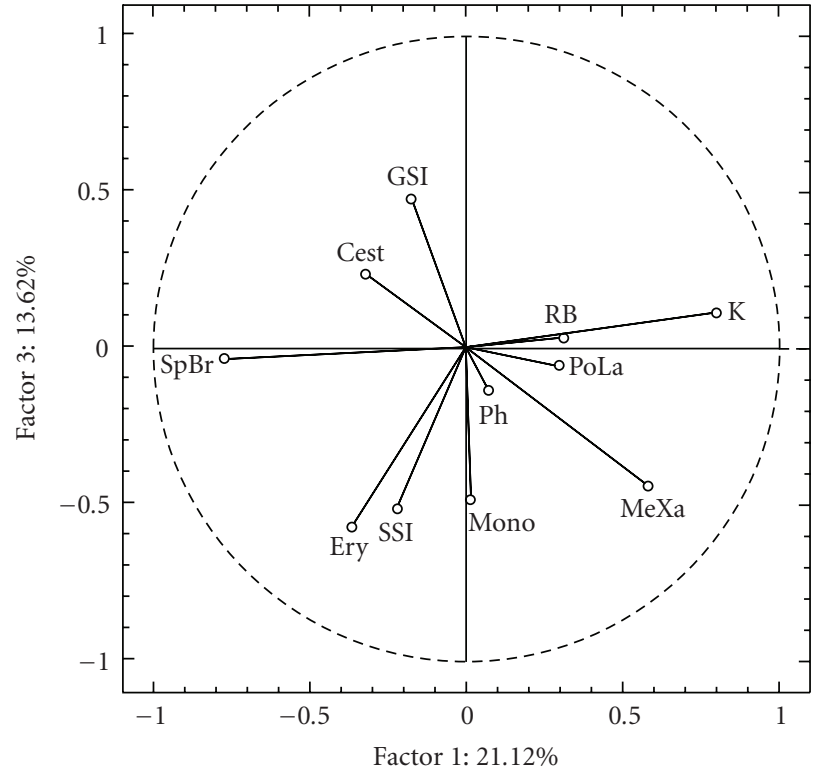

(b)

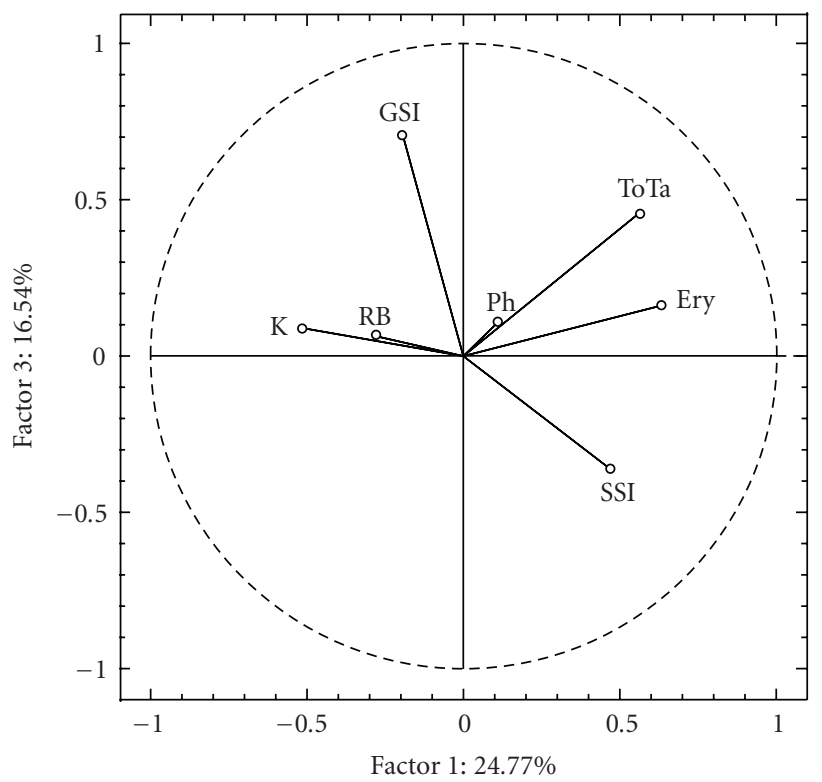

(d)

FIgURE 2: Principal component analysis (PCA) to evaluate the associations within physiology, immunity, and parasitism in before-breeding period. K: condition factor; GSI: gonado-somatic index; SSI: spleen-somatic index; RB: respiratory burst; Ph: phagocyte count; Ery: erythrocyte count; Mono: Monogenea; Cest: Cestoda; MeXa: Metorchis xanthosomus; SpBr: Sphaerostomum bramae; PoLa: Pomporhynchus laevis; ToTa: total parasite species richness.

neutrophiles among the periods investigated. Generally, the acute stress (mainly related to the changes of glucocorticoid level) induces both neutrophilia and lymphopenia in fish [40], although rarely only lymphopenia is reported [41].

In the before-breeding period, we supposed that fish invest more energy into the gonad development. Fish males reached the highest values of GSI before breeding and GSI sharply decreased in spawning. The similar changes as observed for gonad weight measured by gonadosomatic index were observed for relative body weight measured by condition factor among the periods of different reproductive effort. Fish were in the best condition in before-breeding period and subsequently condition factor decreased in spawning and after breeding. Spawning is considered to be physically demanding and stressful period $[28,42,43]$; therefore, we suggest that the fish accumulate its energy reserves before breeding to obtain the sufficient resources for spawning.

Moreover, in spawning period we revealed the highest values of measured immune variables including respiratory 


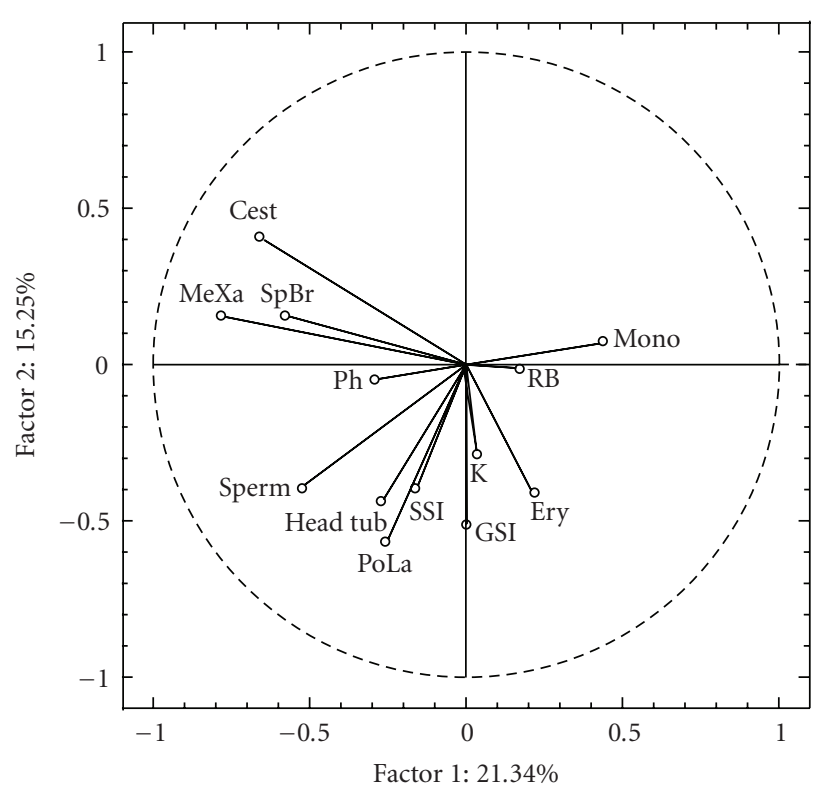

(a)

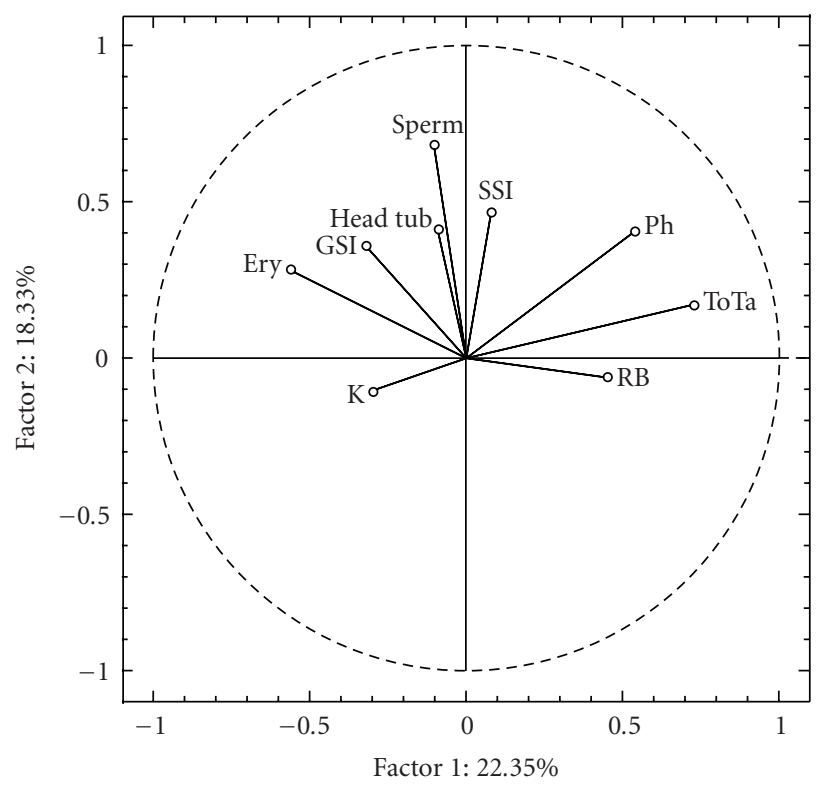

(c)

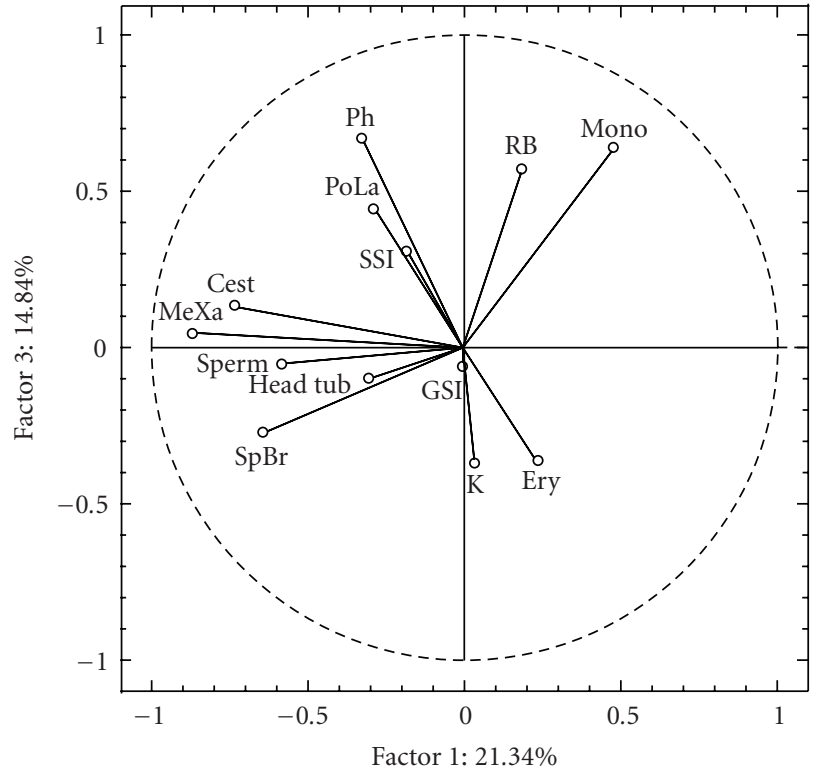

(b)

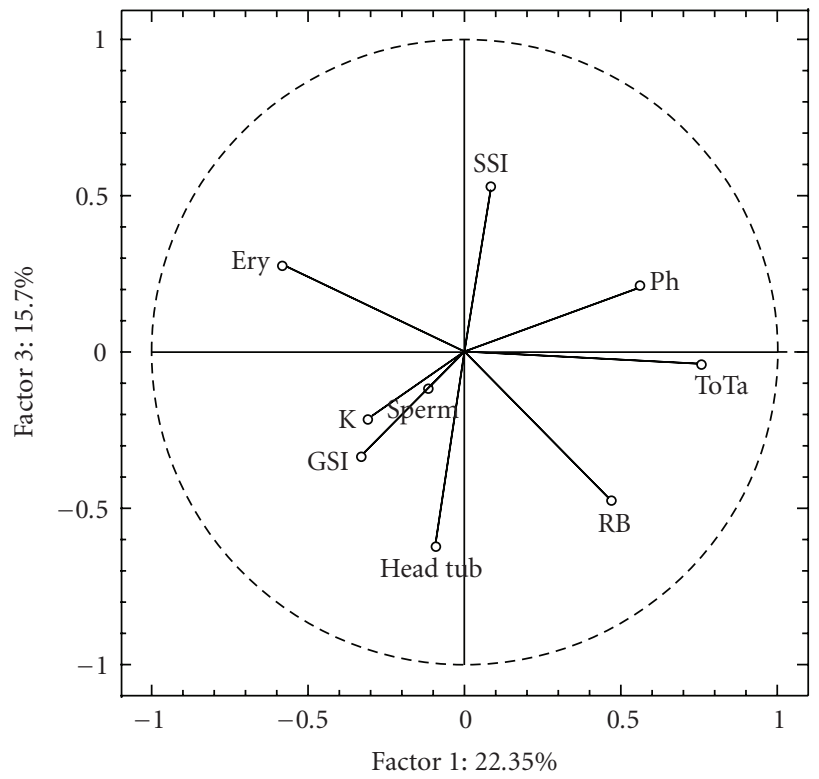

(d)

FIgURE 3: Principal component analysis (PCA) to evaluate the associations within physiology, immunity, and parasitism in breeding period. For abbreviations see legend of Figure 2.

burst, leukocyte count, and leukocrit. An increased number of leukocytes is considered to be common consequence of infection (i.e., [44]). Surprisingly, we found that total parasite diversity is lower in spawning in comparison with before-breeding and after-breeding periods. However, the high values of immune parameters may also reflect the extensive stress due to spawning or alternatively those values may be induced by pathogens, such as protozoa or viruses which were not investigated in the present study.

However, we should take into consideration that fish physiology and immunity is also affected by abiotic as well as biotic factors in each sampled period. Even if the level of steroid hormones is considered to play a key role especially in spawning, fish physiology in a given place and time is influenced also by water temperature, quality of water and other abiotic factors as well as biotic interactions which may influence a current physiological status of individuals.

\subsection{Differences in Parasite Infection and a Link with Immunity.} The parasite life cycle and real infection parameters of parasites within a given host individual or population are influenced by host physiology and immunity (e.g., [4551]). In our study, we tried to evaluate the differences in 


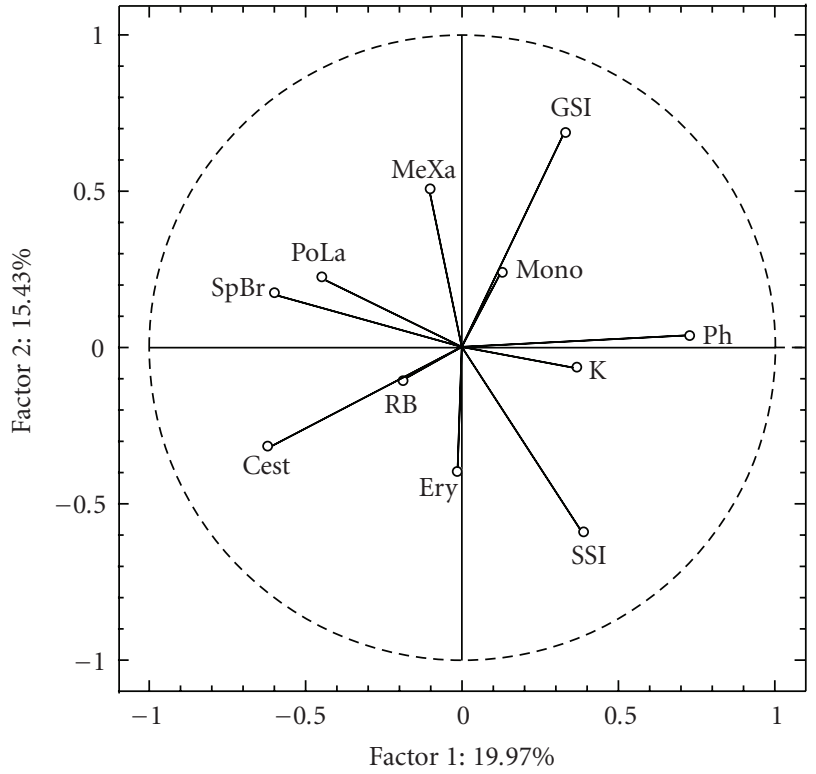

(a)

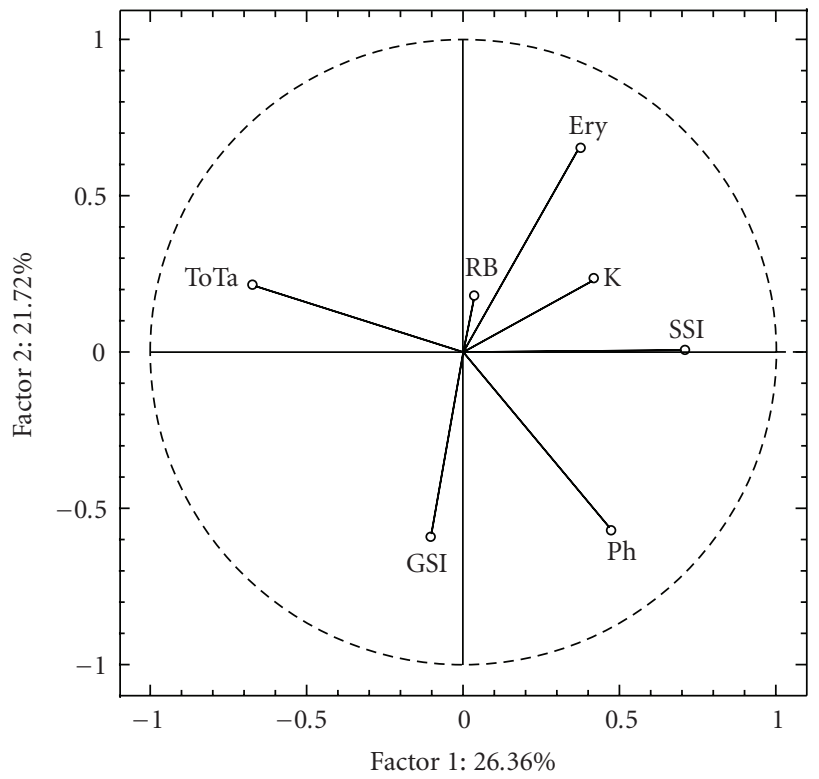

(c)

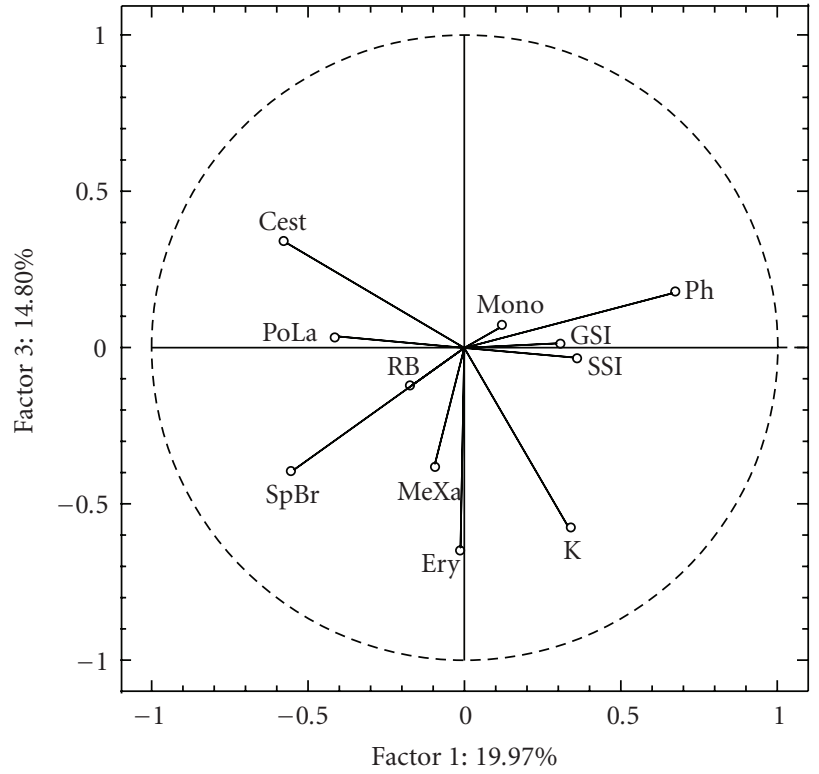

(b)

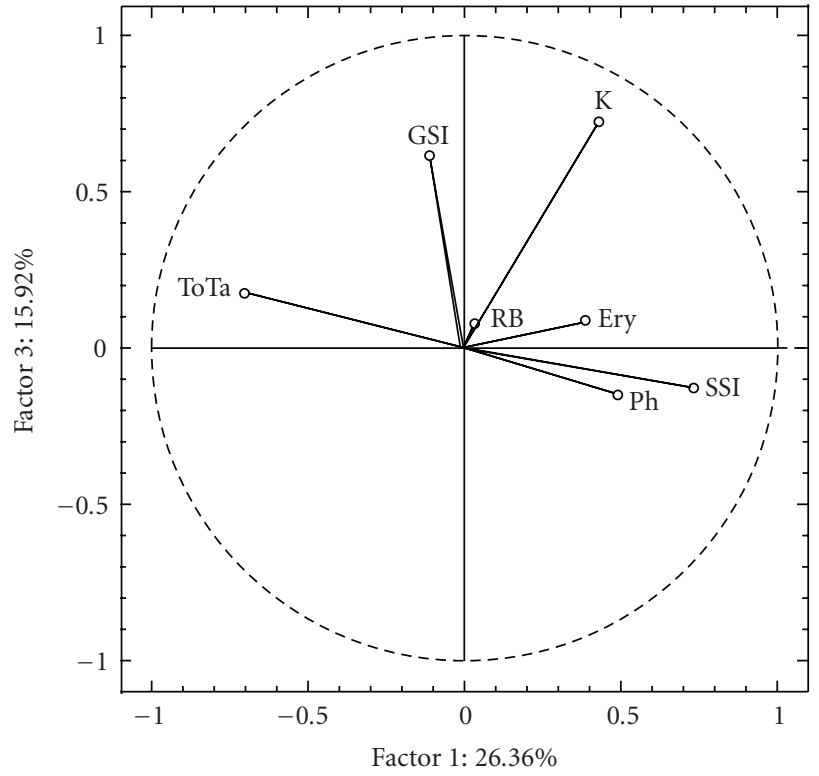

(d)

FIGURE 4: Principal component analysis (PCA) to evaluate the associations within physiology, immunity and parasitism in after-breeding period. For abbreviations see legend of Figure 2.

metazoan parasite infection in three periods which varied in the investment in fish reproduction and likewise we studied the potential associations between selected immune parameters and parasite load.

Abundance of Monogenea (a group of gill and skin parasites) reached relatively high values in before-breeding period, subsequently decreased in breeding, and finally switched over to maximal values in after-breeding period. Although we found no correlation between measured immune variables and infection of Monogenea, we suggest that it is possible that other measurements of immunity (which are not involved in recent immnoecological studies) could reflect the changes in monogenean infection when comparing periods varied in reproductive investment. For example, the production of specific immunoglobulin against gill monogeneans in different fish species (see [49, 52, 53]) or the role of complement for parasite infection in salmonid fishes was shown in experimental studies (e.g., [54-56]). The association between infection by the gill or skin monogeneans and mucus lysozyme activity was also found $[52,57,58]$. Further, parasites dispose of various mechanisms whereby evade or cope with fish immune response. For instance, several species of monogeneans look for host sites where the immune response is not strong 
TABLE 4: The axes of PCA explaining the total variability in the date set.

\begin{tabular}{lllll}
\hline Period & Parasitism measure & axis 1 & axis 2 & axis 3 \\
\hline \multirow{2}{*}{ Before-breeding } & Parasite abundance & 21.12 & 14.19 & 13.62 \\
& Species richness & 24.77 & 20.62 & 16.54 \\
\hline \multirow{2}{*}{ Breeding } & Parasite abundance & 21.34 & 15.25 & 14.84 \\
& Species richness & 22.35 & 18.33 & 15.78 \\
\hline \multirow{2}{*}{ After-breeding } & Parasite abundance & 19.97 & 15.43 & 14.80 \\
& Species richness & 26.36 & 21.72 & 15.92 \\
\hline
\end{tabular}

enough to kill them. Other parasites seem to have evolved and adapted their life cycles with host age or season in which the host immune system is weaker (see [59]) or the monogeneans incorporate the host molecules into their surface to evade host immune system [49].

As mentioned above, the immune parameters are also influenced by water temperature and other environmental factors (e.g., [60-66]). For instance, Poisot et al. [67] investigated the effect of several immune parameters on metazoan parasite abundance in chub after winterizing period associated with a rapid temperature increase. They did not find any correlation between mucus activity and monogeneans, the most numerous metazoan parasite group, whose infection is expected to be associated with mucous activity. However, they found a positive correlation between respiratory burst and parasitism. A positive association between respiratory burst and monogenean abundance was also found in seasonal study of chub [68], which showed a decrease for both immune and parasite variables in November and increase toward spring and summer. Although the highest values of respiratory burst in our study were observed in breeding period, surprisingly the level of infection by monogeneans was low. We could hypothesize that spawning behaviour in chub prevents transmission of gill and skin parasites with direct life cycle. However, such hypothesis should be tested in future. High increase of monogenean abundance in after-breeding period suggests that fish weakened by spawning become more susceptible to monogenean infection. The measured immune parameters in after-breeding period reached the lower values in comparison with breeding period. Therefore, we suppose that the values of measured immune parameters during the breeding reflect the stress caused by spawning rather than current parasite infection.

Concerning Cestoda, a group of intestinal parasites, the decrease in abundance was revealed in breeding period when comparing with before-breeding period. Those results could indicate the temporal presence of intermediate hosts (i.e., [69]) or reflect the changes associated with parasite life cycle. For instance, Scholz and Moravec [70] recorded reaching maximum values of prevalence and mean intensity of Proteocephalus torulosus in March whilst no parasites occurred in fish during summer and autumn. However, our study showed that this cestode species is present in all periods varying in reproductive investment in fish. It is possible that current infection by Cestodes is reflected in other immune defence mechanisms than the ones investigated in our study. In the reviews by Secombes and Chappell [46] and Alvarez-Pellitero [71], the various immune mechanisms against helminths have been summarized (incl. Cestoda), that is, antibody, inflammation, or complement response, which may be caused by parasite infection. Finally, as already mentioned, no relationship between infections of Cestoda and measured immune variables may be related to parasite invasion mechanisms, especially "antigen-based strategies." For instance, Bothriocephalus scorpii have the ability to bind C-reactive protein to avoid the recognition by host's immune system [72].

Total abundance of Digenea reached the maximal values in before-breeding period and decreased toward afterbreeding period. Two numerous digenean parasite species, Sphaerostomum bramae and Metorchis xanthosomus, were analyzed separately regarding the differences within host location and life strategy. Chub investigated in our study was parasitized by Sphaerostomum bramae adults, located in intestine, and larval stages of Metorchis xanthosomus, located in skin. Concerning Sphaerostomum bramae, we found the significantly highest abundance in before-breeding period, decreased values in breeding, and subsequently marked decrease after breeding (not shown in results). Evans [73] showed the high infection level of immature Sphaerostomum bramae during autumn and winter, subsequently rapid maturation of these parasites in spring, which was accompanied by decrease in infection level. Further, abundance of Metorchis xanthosomus also significantly changed among three periods investigated in our study reaching the high values in before-breeding period, maximal values in breeding period, and sharp decrease in after-breeding period. The larval stages of Diplostomum sp. represent other digenean species infecting chub. For this parasite species we observed no significant difference when comparing three periods of different reproductive investments. Diplostomum species belongs to the group of fish parasites that develop in immunoprivileged host tissues, that is, eye in this case, where host barriers prevent or limit the immune response [74]. This may explain why no associations with measured immune parameters were found in our study of chub.

Abundance of Pomporhynchus laevis, intestinal "spinyheaded" worms, was positively correlated to SSI as well as to leukocyte count (not seen in results). Although a little information is available on immune reactions to acanthocephalan parasites of fishes, helminth infections may significantly alter the number of leucocytes in the circulation as well as in lymphoid organs, such as the spleen and kidney $[45,75,76]$.

\subsection{Trade-Off between Immunity and Reproduction and the} Role of Parasites. The central hypothesis of our study is a trade-off between immune response and other physiological demands because of limited energy resources for each organism. Therefore, we estimated the costs of reproduction paid by weakened immune response. If the immunity and reproduction are traded off, the potential associations between those traits are expected. Moreover, we could 
suppose that an individual, which immunity is weakened, should be more susceptible to the infection by pathogens and parasites.

Following the prediction of energy allocation, we expected the trade-off between immunity and reproduction during the before-breeding period, considering the high investment in gonad development. Even if the correlation between GSI and relative spleen size was not significant, we found a trend for negative association between those variables. On the other hand, no trend of association between GSI and SSI was found in breeding and afterbreeding periods. Using PCA, the total parasite species richness was positively associated with SSI, which suggests that hosts parasitized by wider spectrum of parasite species dispose a large spleen because they invested more energy in immune defence. The positive correlation between spleen size and species richness of nematode parasites was found in interspecies study of males birds, using comparative analysis, suggesting a causative role for parasitic nematodes in the evolution of avian spleen size [77]. Concerning fish, the positive correlation between spleen size and parasite abundance was found in interspecific comparative study of cyprinid fish for females although the correlation was lacking for males [78]. Surprisingly, using PCA and Pearson correlation we found the reverse relationships between fish condition and two most abundant digenean parasites in before-breeding period. Condition factor was negatively correlated with abundance of Sphaerostomum bramae and positively with Metorchis xanthosomus. As mentioned above, these two parasite species differ in strategy and location within fish host. Sphaerostomum bramae is an adult living in intestine of definitive host. On the other hand, metacercariae of Metorchis xanthosomus parasitizing in fish skin are longlife, resting, and intermediate stages of the parasite. Fish as intermediate host infected by metacercariae of Metorchis species are ingested by the definitive host (i.e., carnivores feeding in aquatic habitats). Thus, the different relationship between the abundance of those digenean parasite species and condition factor could be explained by a different parasite life strategy.

In spawning period, following the sperm protection hypothesis [16, 17], we expected and confirmed that fish males highly investing into the spawning ornamentation, that is, breeding tubercles, possess the sperm of a better quality (measured by spermatocrite) than less ornamented males. Such males should be more susceptible to the diseases regarding weakened immunity. In accordance with this prediction, we found that males with high spermatocrite values dispose of large spleen. Moreover, fish males with high spermatocrite value were parasitized by higher number of digenean species Metorchis xanthosomus parasitizing fish skin. Due to potential immunosuprresion by testosterone as highlighted by immunocompetence handicap hypothesis $[15,79]$, immunity of males should be weakened when investing more extensively in spawning ornamentation, and then, those males should be more parasitized. Our results partially confirmed the immunocompetence handicap hypothesis. A significant positive correlation between number of head breeding tubercles and abundance of digenean parasites Sphaerostomum bramae was found. Even if no relationship was found between head tubercles and parasite species richness or abundance, the significant positive correlation between the immune measures and parasitism was found in spawning.

In after-breeding period we expected and confirmed that condition status of fish decreased when comparing with breeding period. Fish are weakened after spawning and this may explain the increase of monogenean abundance due to relatively rapid direct life cycle. The investment in somatic condition seems to play an important role for parasite establishing. This may explain the fact that fish in worse condition are more parasitized by Cestoda. The immunity is no more suppressed by steroid hormones in this period. We found a negative correlation between phagocyte count and both parasite abundance (Cestoda and Sphaerostomum bramae) and total parasite species richness. Generally, the high immune response (i.e., high number of phagocytes in this case) leads to the decrease of parasite infection. However, Viney et al. [80] highlighted the fact that due to the autoimmunity, "immunologically more" may not mean necessarily "better." Further, it was proposed that rather than the intensity of immune responses, it is recommended to determine the optimal immune response, that is, the effective protection of individuals against infection as well as measurement of individuals' fitness.

\section{Conclusion}

We conclude that the reproductive investments in fish related to breeding play an important role for energy allocation among condition, immunity, and reproduction. The investments in those traits and parasitism differ among before-breeding, breeding, and after-breeding periods. The high values of immune parameters in breeding did not reflect a current infection by metazoan parasites but probably reflect the stress due to spawning or may be caused by protozoan or viral infection. A high reproductive effort associated with spawning leads to higher digenean infection in more ornamented individuals and/or males possessing the sperm of better quality.

\section{Acknowledgments}

This study was supported by the Grant Agency of the Czech Republic, Project no. 524/07/0188. The field study and haematological analyses were partially funded by a Research Project from Masaryk University, Brno, Project no. MSM 0021622416. K. Rohlenová was funded by Rector's Programme in Support of MU Students' Creative Activities. A. Šimková was supported by the Ministry of Education, Youth and Sports of the Czech Republic (Project no. LC522, Ichthyoparasitology Research Centre). The authors thank Martina Pečínková, Martina Dávidová, Radim Blažek, Radim Sonnek, and Eva Řehulková from the Laboratory of Parasitology, Institute of Botany and Zoology, Faculty of Science, Masaryk University, Brno for kindly helping with parasite dissection. They thank Miroslava Palíková from 
the University of Veterinary and Pharmaceutical Sciences, Brno, and Antonín Lojek from the Institute of Biophysics, Academy of Science of the Czech Republic, for their help with immunology and haematology methodology and Pavel Jurajda, Jiří Huml, Michal Janáč, and Matej Polačik from the Institute of Vertebrate Biology, Academy of Science of the Czech Republic, for their valuable assistance in field sampling. They thank the Moravian Anglers Union for supporting the research in their entire district and for purchasing the experimental fish.

\section{References}

[1] D. A. Roff, The Evolution of Life Histories: Theory and Analysis, Chapman \& Hall, New York, NY, USA, 1992.

[2] S. C. Stearns, The Evolution of Life Histories, Oxford University Press, Oxford, UK, 1992.

[3] B. C. Sheldon and S. Verhulst, "Ecological immunology: costly parasite defences and trade-offs in evolutionary ecology," Trends in Ecology \& Evolution, vol. 11, no. 8, pp. 317-321, 1996.

[4] A. P. Møller, "Immune defence, extra-pair paternity, and sexual selection in birds," Proceedings of the Royal Society B, vol. 264, no. 1381, pp. 561-566, 1997.

[5] T. Szép and A. P. Møller, "Cost of parasitism and host immune defence in the sand martin Riparia riparia: a role for parentoffspring conflict?" Oecologia, vol. 119, no. 1, pp. 9-15, 1999.

[6] D. Hasselquist, M. F. Wasson, and D. W. Winkler, "Humoral immunocompetence correlates with date of egg-laying and reflects work load in female tree swallows," Behavioral Ecology, vol. 12, no. 1, pp. 93-97, 2001.

[7] A. P. Møller and N. Saino, "Immune response and survival," Oikos, vol. 104, no. 2, pp. 299-304, 2004.

[8] N. Hillgarth, M. Ramenofsky, and J. Wingfield, "Testosterone and sexual selection," Behavioral Ecology, vol. 8, no. 1, pp. 108112, 1997.

[9] F. Skarstein, I. Folstad, and S. Liljedal, "Whether to reproduce or not: Immune suppression and costs of parasites during reproduction in the Arctic charr," Canadian Journal of Zoology, vol. 79, no. 2, pp. 271-278, 2001.

[10] E. Ottová, A. Šimková, P. Jurajda, et al., "Sexual ornamentation and parasite infection in males of common bream (Abramis brama): a reflection of immunocompetence status or simple cost of reproduction?" Evolutionary Ecology Research, vol. 7, no. 4, pp. 581-593, 2005.

[11] W. D. Hamilton and M. Zuk, "Heritable true fitness and bright birds: a role for parasites?" Science, vol. 218, no. 4570, pp. 384387, 1982.

[12] W. J. Hamilton and R. Poulin, "The Hamilton and Zuk hypothesis revisited: a meta-analytical approach," Behaviour, vol. 134, no. 4-5, pp. 299-320, 1997.

[13] A. P. Møller, P. Christe, and E. Lux, "Parasitism, host immune function, and sexual selection," Quarterly Review of Biology, vol. 74, no. 1, pp. 3-20, 1999.

[14] M. L. Roberts, K. L. Buchanan, and M. R. Evans, "Testing the immunocompetence handicap hypothesis: a review of the evidence," Animal Behaviour, vol. 68, no. 2, pp. 227-239, 2004.

[15] I. Folstad and A. J. Karter, "Parasites, bright males, and the immunocompetence handicap," American Naturalist, vol. 139, no. 3, pp. 603-622, 1992.
[16] I. Folstad and F. Skarstein, "Is male germ line control creating avenues for female choice?" Behavioral Ecology, vol. 8, no. 1, pp. 109-112, 1997.

[17] S. Liljedal, I. Folstad, and F. Skarstein, "Secondary sex traits, parasites, immunity and ejaculate quality in the Arctic charr," Proceedings of the Royal Society B, vol. 266, no. 1431, pp. 18931898, 1999.

[18] R. Kortet, A. Vainikka, M. J. Rantala, and J. Taskinen, "Sperm quality, secondary sexual characters and parasitism in roach (Rutilus rutilus L.)," Biological Journal of the Linnean Society, vol. 81, no. 1, pp. 111-117, 2004.

[19] V. Baruš and O. Oliva, Lampreys (Petromyzones) and Fishes (Osteichthyes). Fauna of the Czech and Slovak Republics, Academia, Praha, Czech Republic, 1995.

[20] M. L. Wiley and B. B. Collette, "Breeding tubercles and contact organs in fishes: their occurrence, structure and significance," Bulletin of the American Museum of Natural History, vol. 143, no. 3, pp. 143-216, 1970.

[21] R. Kortet, J. Taskinen, A. Vainikka, and H. Ylönen, "Breeding tubercles, papillomatosis and dominance behaviour of male roach (Rutilus rutilus) during the spawning period," Ethology, vol. 110, no. 8, pp. 591-601, 2004.

[22] C. Wedekind, "Detailed information about parasites revealed by sexual ornamentation," Proceedings of the Royal Society B, vol. 247, no. 1320, pp. 169-174, 1992.

[23] J. Taskinen and R. Kortet, "Dead and alive parasites: sexual ornaments signal resistance in the male fish, Rutilus rutilus," Evolutionary Ecology Research, vol. 4, no. 6, pp. 919-929, 2002.

[24] F. Skarstein and I. Folstad, "Sexual dichromatism and the immunocompetence handicap: an observational approach using Arctic charr," Oikos, vol. 76, no. 2, pp. 359-367, 1996.

[25] H. Modrá, Z. Svobodová, and J. Koláŕová, "Comparison of differential leukocyte counts in fish of economic and indicator importance," Acta Veterinaria Brno, vol. 67, no. 4, pp. 215-226, 1998.

[26] L. Kubala, A. Lojek, M. Číž, J. Vondráček, M. Dušková, and H. Slavíková, "Determination of phagocyte activity in whole blood of carp (Cyprinus carpio) by luminol-enhanced chemiluminescence," Veterinarni Medicina, vol. 41, no. 10, pp. 323-327, 1996.

[27] R. Ergens and J. Lom, Causative Agents of Parasitic Fish Diseases, Academia, Prague, Czech Republic, 1970.

[28] T. Bolger and P. L. Connolly, "The selection of suitable indices for the measurement and analysis of fish condition," Journal of Fish Biology, vol. 34, no. 2, pp. 171-182, 1989.

[29] A. V. Gusev, "Metazoan parasites-part I," in Identification Key to Parasites of Freshwater Fish, O. N. Bauer, Ed., vol. 2, p. 424, Nauka, Leningrad, Russia, 1985.

[30] I. A. Khotenovsky, Fauna of the SSSR, Monogenea, Nauka, Leningrad, Russia, 1985.

[31] T. Scholz, "Amphilinida and Cestoda, parasites of fish in Czechoslovakia," Acta Scientiarum Naturalium Academiae Scientiarum Bohemicae Brno, vol. 23, no. 4, pp. 1-56, 1989.

[32] F. Moravec, Parasitic Nematodes of Freshwater Fishes of Europe, Academia and Kluwer Academic Publishers, Praha, Czech Republic, 1994.

[33] B. Georgiev, V. Bisekov, and T. Genov, "The staining method for cestodes with iron acetocarmine," Helminthologia, vol. 23, pp. 279-281, 1986.

[34] Z. Svobodová, D. Pravda, and J. Paláčková, Unified Methods of Haematological Examination of Fish, vol. 22, Manuals of Research Institute of Fish Culture and Hydrobiology, University of South Bohemia, Vodňany, Czech Republic, 1991. 
[35] Z. Svobodová, D. Pravda, and J. Paláčková, Universal Methods of Haematological Investigations in Fish, Edice Metodik, no. 22, VÚRH, Vodňany, Czech Republic, 1986.

[36] V. Lusková, "Annual cycles and normal values of hematological parameters in fishes," Acta Scientiarum Naturalium Academiae Scientiarum Bohemicae Brno, vol. 31, no. 5, p. 70, 1997.

[37] J. Šterzl, The Immune System and Its Physiological Functions, Czech Society for Immunology, Prague, Czech Republic, 1993.

[38] A. O. Bush, K. D. Lafferty, J. M. Lotz, and A. W. Shostak, "Parasitology meets ecology on its own terms: margolis et al. revisited," Journal of Parasitology, vol. 83, no. 4, pp. 575-583, 1997.

[39] G. A. Wedemeyer, B. A. Barton, and D. J. McLeay, "Stress and acclimation," in Methods for Fish Biology, C. B. Schreck and P. B. Moyle, Eds., pp. 451-489, American Fisheries Society, Bethesda, Md, USA, 1990.

[40] A. L. Pulsford, S. Lemaire-Gony, M. Tomlinson, N. Collingwood, and P. J. Glynn, "Effects of acute stress on the immune system of the dab, Limanda limanda," Comparative Biochemistry and Physiology C, vol. 109, no. 2, pp. 129-139, 1994.

[41] A. Larsson, K. J. Lehtinen, and C. Haux, "Biochemical and hematological effects of a titanium dioxide industrial effluent on fish," Bulletin of Environmental Contamination and Toxicology, vol. 25, no. 3, pp. 427-435, 1980.

[42] K. R. Munkittrick and J. F. Leatherland, "Haematocrit values in feral goldfish, Carassius auratus L., as indicators of the health of the population," Journal of Fish Biology, vol. 23, pp. 153-161, 1982.

[43] P. W. Wester, A. D. Vethaak, and W. B. van Muiswinkel, "Fish as biomarkers in immunotoxicology," Toxicology, vol. 86, no. 3, pp. 213-232, 1994.

[44] A. E. Ellis, "The function of teleost fish lymphocytes in relation to inflammation," International Journal of Tissue Reactions, vol. 8, no. 4, pp. 263-270, 1986.

[45] D. T. Richards, D. Hoole, J. W. Lewis, E. Evans, and C. Arme, "Changes in the cellular composition of the spleen and pronephros of carp Cyprinus carpio infected with the blood fluke Sanguinicola inermis (Trematoda: Sanguinicolidae)," Diseases of Aquatic Organisms, vol. 19, no. 3, pp. 173-179, 1994.

[46] C. J. Secombes and L. H. Chappell, "Fish immune responses to experimental and natural infection with helminth parasites," Annual Review of Fish Diseases, vol. 6, pp. 167-177, 1996.

[47] K. Buchmann, "Immune mechanisms in fish skin against monogeneans-a model," Folia Parasitologica, vol. 46, no. 1, pp. 1-9, 1999.

[48] S. R. M. Jones, "The occurrence and mechanisms of innate immunity against parasites in fish," Developmental and Comparative Immunology, vol. 25, no. 8-9, pp. 841-852, 2001.

[49] K. Buchmann and T. Lindenstrøm, "Interactions between monogenean parasites and their fish hosts," International Journal for Parasitology, vol. 32, no. 3, pp. 309-319, 2002.

[50] T. K. Hatice, Z. Erdogan, and R. Coz-Rakovac, "The occurrence of Ligula intestinalis (L.) observed in chub (Leuciscus cephalus L.) from Caparlipatlak Dam lake, Ivrindi-Balikesir, Turkey," Periodicum Biologorum, vol. 108, no. 2, pp. 183-187, 2006.

[51] G. Muñoz, A. S. Grutter, and T. H. Cribb, "Structure of the parasite communities of a coral reef fish assemblage (Labridae): testing ecological and phylogenetic host factors," Journal of Parasitology, vol. 93, no. 1, pp. 17-30, 2007.
[52] V. L. Vladimirov, "The immunity of fishes in the case of dactylogyrosis," Parasitologiya, vol. 5, pp. 51-58, 1971 (Russian).

[53] K. Buchmann, "A note on the humoral immune response of infected Anguilla anguilla against the gill monogenean Pseudodactylogyrus bini," Fish \& Shellfish Immunology, vol. 3, no. 5, pp. 397-399, 1993.

[54] K. Buchmann, "Binding and lethal effect of complement from Oncorhynchus mykiss on Gyrodactylus derjavini (Platyhelminthes: Monogenea)," Diseases of Aquatic Organisms, vol. 32, no. 3, pp. 195-200, 1998.

[55] P. D. Harris, A. Soleng, and T. A. Bakke, "Killing of Gyrodactylus salaris (Platyhelminthes, Monogenea) mediated by host complement," Parasitology, vol. 117, no. 2, pp. 137-143, 1998.

[56] M. Rubio-Godoy, R. Porter, and R. C. Tinsley, "Evidence of complement-mediated killing of Discocotyle sagittata (Platyhelminthes, Monogenea) oncomiracidia," Fish \& Shellfish Immunology, vol. 17, no. 2, pp. 95-103, 2004.

[57] K. Buchmann and A. Uldal, "Gyrodactylus derjavini infections in four salmonids: comparative host susceptibility and site selection of parasites," Disease of Aquatic Organisms, vol. 28, no. 3, pp. 201-209, 1997.

[58] K. Buchmann and J. Bresciani, "Microenvironment of Gyrodactylus derjavini on rainbow trout Oncorhynchus mykiss: association between mucous cell density in skin and site selection," Parasitology Research, vol. 84, no. 1, pp. 17-24, 1997.

[59] A. Sitja-Bobadilla, "Living off a fish: a trade-off between parasites and the immune system," Fish \& Shellfish Immunology, vol. 25, no. 4, pp. 358-372, 2008.

[60] J. E. Bly and L. W. Clem, "Temperature and teleost immune functions," Fish \& Shellfish Immunology, vol. 2, no. 3, pp. 159171, 1992.

[61] M. E. Collazos, E. Ortega, and C. Barriga, "Effect of temperature on the immune system of a cyprinid fish (Tinca tinca, L). Blood phagocyte function at low temperature," Fish \& Shellfish Immunology, vol. 4, no. 3, pp. 231-238, 1994.

[62] T. H. Hutchinson and M. J. Manning, "Seasonal trends in serum lysozyme activity and total protein concentration in dab (Limanda limanda L.) sampled from Lyme Bay, U.K," Fish \& Shellfish Immunology, vol. 6, no. 7, pp. 473-482, 1996.

[63] G. Scapigliati, D. Scalia, A. Marras, S. Meloni, and M. Mazzini, "Immunoglobulin levels in the teleost sea bass Dicentrarchus labrax (L.) in relation to age, season, and water oxygenation," Aquaculture, vol. 174, no. 3-4, pp. 207-212, 1999.

[64] A. L. Langston, R. Hoare, M. Stefansson, R. Fitzgerald, H. Wergeland, and M. Mulcahy, "The effect of temperature on non-specific defence parameters of three strains of juvenile Atlantic halibut (Hippoglossus hippoglossus L.)," Fish \& Shellfish Immunology, vol. 12, no. 1, pp. 61-76, 2002.

[65] A. Hernández and L. Tort, "Annual variation of complement, lysozyme and haemagglutinin levels in serum of the gilthead sea bream Sparus aurata," Fish \& Shellfish Immunology, vol. 15, no. 5, pp. 479-481, 2003.

[66] T. J. Bowden, R. Butler, and I. R. Bricknell, "Seasonal variation of serum lysozyme levels in Atlantic halibut (Hippoglossus hippoglossus L.)," Fish \& Shellfish Immunology, vol. 17, no. 2, pp. 129-135, 2004.

[67] T. Poisot, A. Šimková, P. Hyršl, and S. Morand, "Interactions between immunocompetence, somatic condition and parasitism in the chub Leuciscus cephalus in early spring," Journal of Fish Biology, vol. 75, no. 7, pp. 1667-1682, 2009. 
[68] K. Lamková, A. Šimková, M. Palíková, P. Jurajda, and A. Lojek, "Seasonal changes of immunocompetence and parasitism in chub (Leuciscus cephalus), a freshwater cyprinid fish," Parasitology Research, vol. 101, no. 3, pp. 775-789, 2007.

[69] V. Hanzelová and D. Gerdeaux, "Seasonal occurrence of the tapeworm Proteocephalus longicollis and its transmission from copepod intermediate host to fish," Parasitology Research, vol. 91, no. 2, pp. 130-136, 2003.

[70] T. Scholz and F. Moravec, "Seasonal dynamics of Proteocephalus torulosus (Cestoda: Proteocephalidae) in barbel (Barbus barbus) from the Jihlava River, Czech Republic," Folia Parasitologica, vol. 41, no. 4, pp. 253-257, 1994.

[71] P. Alvarez-Pellitero, "Fish immunity and parasite infections: from innate immunity to immunoprophylactic prospects," Veterinary Immunology and Immunopathology, vol. 126, no. 34, pp. 171-198, 2008.

[72] T. C. Fletcher, A. White, and B. A. Baldo, "Isolation of a phosphorylcholine-containing component from the turbot tapeworm, Bothriocephalus scorpii (Müller), and its reaction with C-reactive protein," Parasite Immunology, vol. 2, no. 4, pp. 237-248, 1980.

[73] N. A. Evans, "The occurrence of Sphaerostoma bramae (Digenea: Allocreadiidae) in the roach from the WorcesterBirmingham canal," Journal of Helminthology, vol. 51, no. 3, pp. 189-196, 1977.

[74] M. Kalbe and J. Kurtz, "Local differences in immunocompetence reflect resistance of sticklebacks against the eye fluke Diplostomum pseudospathaceum," Parasitology, vol. 132, no. 1, pp. 105-116, 2006.

[75] A. Murad and S. Mustafa, "Blood parameters of catfish, Heteropneustes fossilis (Bloch), parasitized by metacercariae of Diplostomum sp," Journal of Fish Diseases, vol. 11, no. 4, pp. 365-368, 1988.

[76] M. Taylor and D. Hoole, "Ligula intestinalis (L.) (Cestoda: Pseudophyllidea): plerocercoid-induced changes in the spleen and pronephros of roach, Rutilus rutilus (L.), and gudgeon, Gobio gobio (L.)," Journal of Fish Biology, vol. 34, no. 4, pp. 583-596, 1989.

[77] S. Morand and R. Poulin, "Nematode parasite species richness and the evolution of spleen size in birds," Canadian Journal of Zoology, vol. 78, no. 8, pp. 1356-1360, 2000.

[78] A. Šimková, T. Lafond, M. Ondračková, P. Jurajda, E. Ottová, and S. Morand, "Parasitism, life history traits and immune defence in cyprinid fish from Central Europe," BMC Evolutionary Biology, vol. 8, no. 29, pp. 1-11, 2008.

[79] C. Wedekind and I. Folstad, "Adaptive or nonadaptive immunosuppression by sex hormones?" The American Naturalist, vol. 143, no. 5, pp. 936-938, 1994.

[80] M. E. Viney, E. M. Riley, and K. L. Buchanan, "Optimal immune responses: immunocompetence revisited," Trends in Ecology \& Evolution, vol. 20, no. 12, pp. 665-669, 2005. 

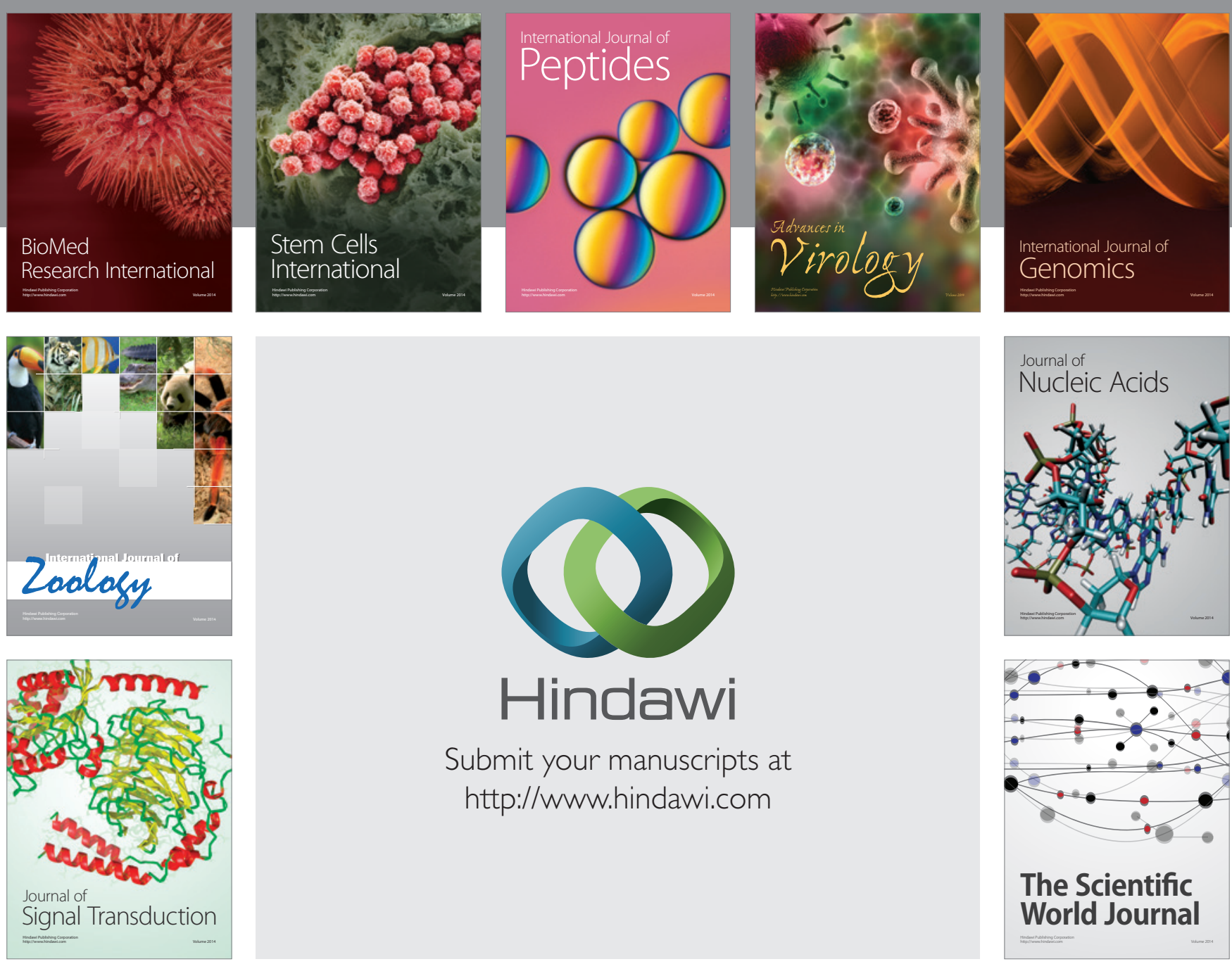

Submit your manuscripts at

http://www.hindawi.com
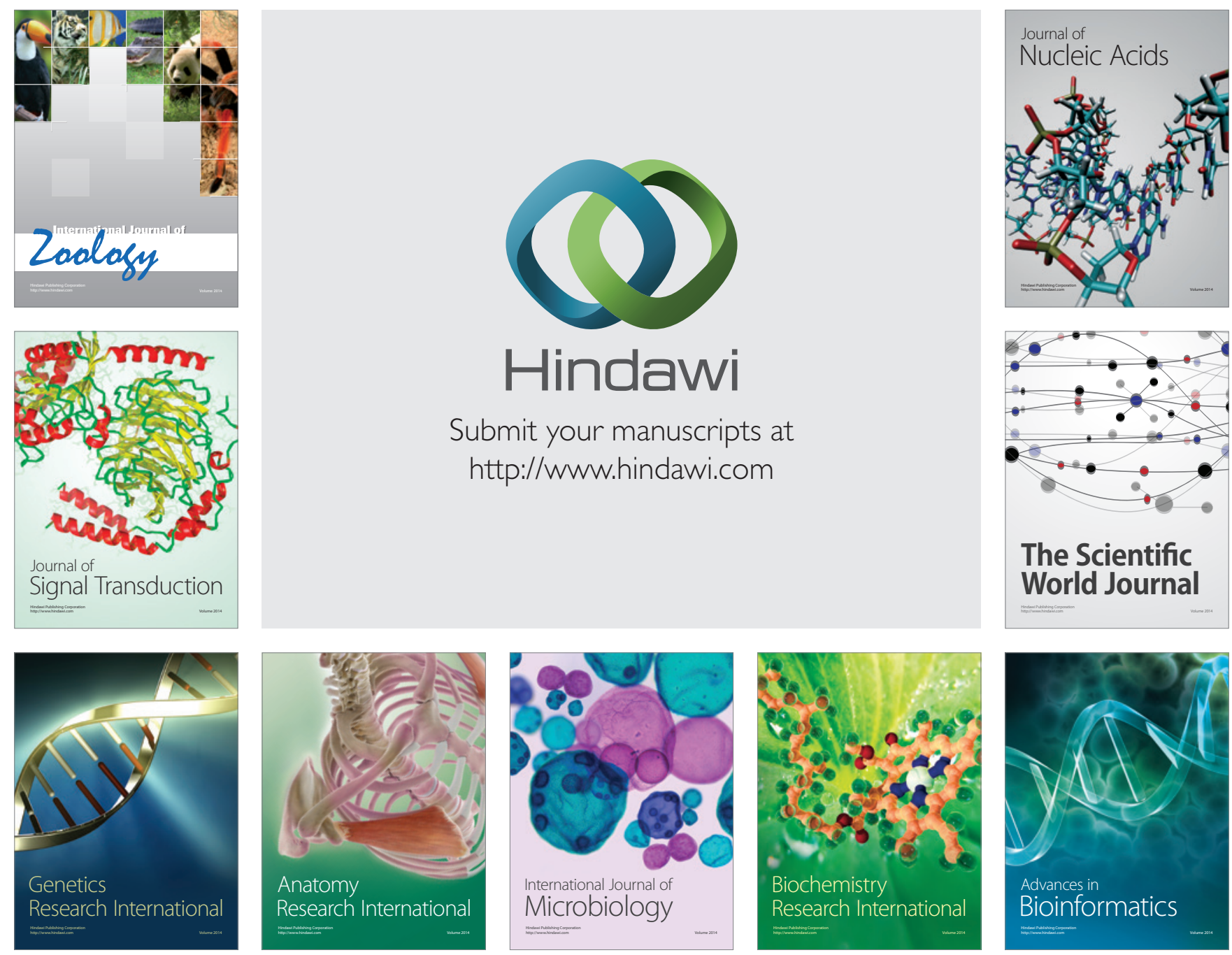

The Scientific World Journal
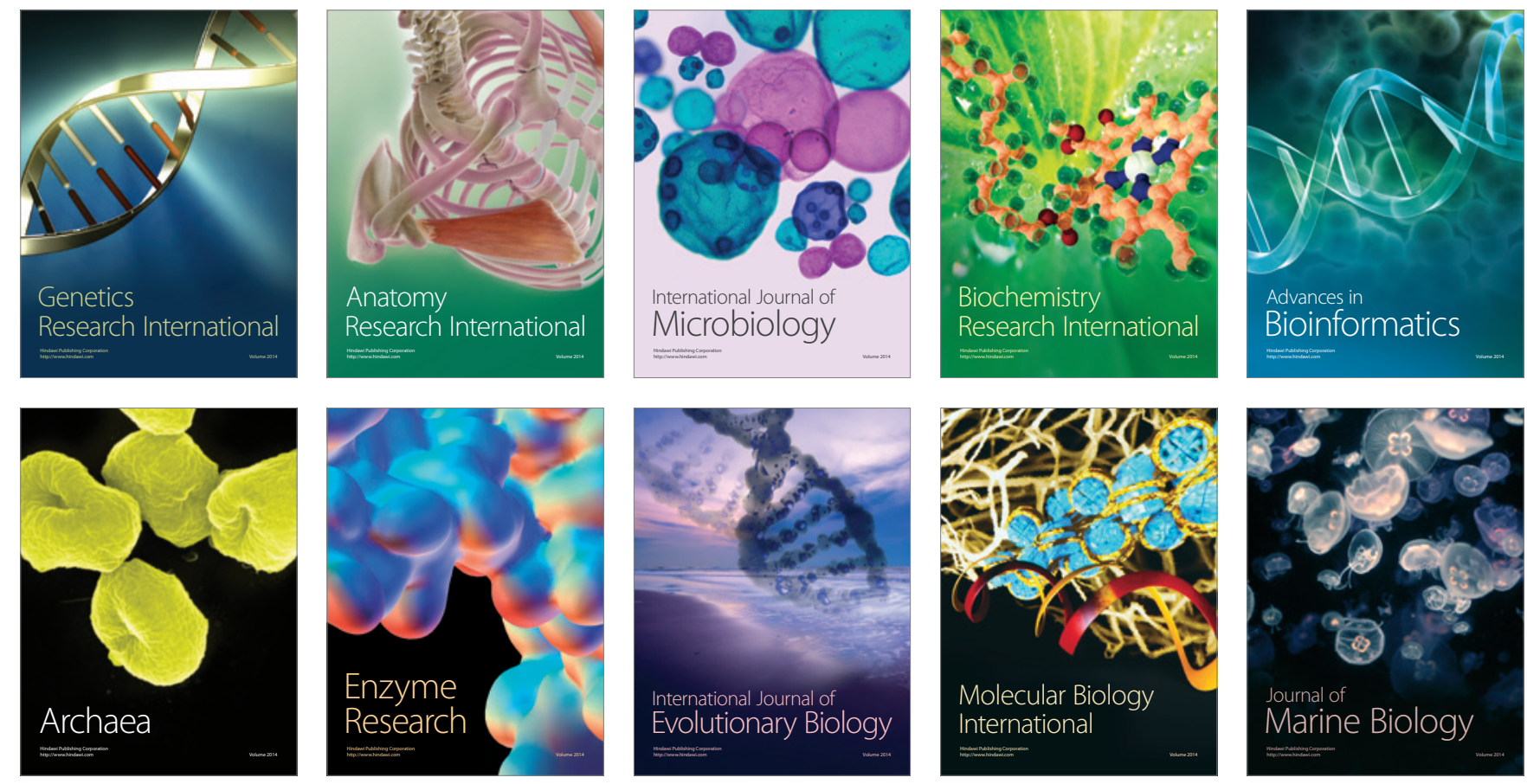